\section{EVERYTHING YOU NEED FOR DECONTAMINATION}

Henry Schein Dental's experienced team of decontamination specialists has all the in-depth knowledge needed to help guide you through every aspect of the decontamination process, ensuring compliance with HTM 01-05 guidelines.

The expert team understands how instruments should flow through the decontamination process from surgery to LDU (Local Decontamination Unit), and in conjunction with their in-house equipment specialists, can plan layouts and install equipment that makes optimal use of available space. Henry Schein Dental's outstanding array of decontamination equipment includes Melag washer disinfectors and autoclaves, which, along with infection control consumables from all the UK's leading suppliers, means that all your cleaning and sterilisation supplies can be found in one, convenient place.

Henry Schein Dental's aim is to supply 'Everything Dental' that a practice needs to be successful and profitable. An important part of this is to educate practice teams and they run several events on decontamination and HTM 01-05. Events available include evening courses at locations nationwide, interactive core CPD in-practice training for your team and the new City \& Guilds accredited course, Cross Infection and Decontamination.

For 2015 dates and venues visit www.henryschein. co.uk/education.

\title{
EASY COMMUNICATION BETWEEN DENTIST AND LAB
}

Take digital impressions and order the restoration online, quickly and easily via the global Sirona Connect portal. Sirona Connect is the first innovative system for digital cooperation between dentists and dental labs. The rapidly growing number of users is creating a true boom in orders - this year Sirona anticipates a 60\% increase in orders around the world.

Sirona Connect allows dentists and dental technicians to connect in a very modern way - they can exchange data conveniently and securely via the portal. The portal interface is integrated into the dentist's and technician's software, regardless of which software version is being used by either party, thus greatly facilitating workflow.

More and more dentists and dental technicians are using this service and the anticipated 60\% more orders than last year via the portal correspond to around 100,000 restorations.

Sirona Connect portal is now available in a total of eight languages. Dentists and dental technicians can communicate via the portal provided by Sirona. In addition to German and English, the available languages include French, Italian, Spanish, Chinese, Korean, and Portuguese.

For further information call Sirona Dental Systems on 0845 0715040 or email info@sironadental.co.uk.

\section{ALL THE TOOLS YOU NEED}

As announced at this year's BDIA Dental Showcase, Carestream Dental is soon to roll out its exciting new CS R4 Springboard across the UK.

Delivering data in real-time for an up-to-the-minute analysis of the practice's performance, the technology is designed to evaluate, monitor and action KPIs to help you manage your success with outstanding accuracy.

The core areas covered will include occupancy; to optimise chair time, treatment; to improve treatment uptake, confirmation; to reduce no-shows, and recare; to enable effective management of appointment reminders.

What's more, all practices currently using the CS R4 Clinical+ practice management software will receive an upgrade to $\mathrm{R} 4$ Springboard in January 2015, completely free of charge!

Giving you the tools you need to measure your current performance and enhance your practice, find out more about the CS R4 Springboard from Carestream Dental today.

For more information, contact Carestream Dental on 0800169 9692 or visit www.carestreamdental.co.uk.

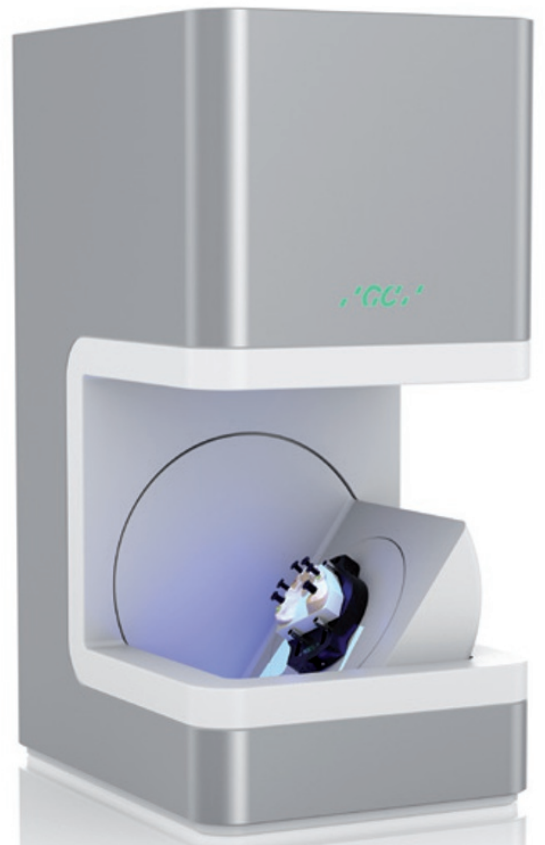

\section{FLEXIBLE, INTUITIVE, FUNCTIONAL SCANNER THAT OPTIMISES PRODUCTIVITY}

With the newly developed GC Aadva high-end lab scanner, GC is set to expand its presence into the area of digital dentistry.

The GC Aadva Lab Scanner is a full automated lab scanner using the most recent projection and measurement technology. The use of a high-end dual camera system with blue LED structured light in combination with GC's implant scan-technology assures the highest accuracy and extremely fast scanning of objects.

Implant supported frameworks require the highest accuracy level from your scanner and design creativity from your CAD software. A perfect and passive fit of implant frameworks when seated is a clinical prerequisite. GC's Aadva lab scanner offer it all and within a very short time. Thanks to the use of the unique GC Scan flags the capture of implant positions and orientations with the highest accuracy is achievable within seconds. The result is a high precision virtual model and the perfect base for the Aadva CAD design if extremely complex geometries such as bars and implant supported screw retained frameworks.

Aadva is flexible, intuitive and functional. It meets any clinical case from crowns to implant supported frameworks. Optimise your productivity with a few clicks!

For further information about the scanner contact GC UK on 01908218999. 